\title{
The DPSIR Approach for Coastal Risk Assessment under Climate Change at Regional Scale: The Case of Apulian Coast (Italy)
}

\author{
Maria Francesca Bruno ${ }^{1, *(\mathbb{C}}$, Alessandra Saponieri ${ }^{2}{ }^{(0)}$, Matteo Gianluca Molfetta ${ }^{1}(\mathbb{C}$ \\ and Leonardo Damiani ${ }^{1}$ (D) \\ 1 Department of Civil, Environmental, Building Engineering and Chemistry, Polytechnic University of \\ Bari-Via E. Orabona, 4, 70125 Bari, Italy; matteogianluca.molfetta@poliba.it (M.G.M.); \\ leonardo.damiani@poliba.it (L.D.) \\ 2 Department of Engineering for Innovation, University of Salento, Ecotekne, 73047 Lecce, Italy; \\ alessandra.saponieri@unisalento.it \\ * Correspondence: mariafrancesca.bruno@poliba.it; Tel.: +39-080-4605-207
}

Received: 7 June 2020; Accepted: 17 July 2020; Published: 18 July 2020

\begin{abstract}
In the present paper, the coastal risk is assessed, at a regional scale, to produce a risk map that will help to prioritize policies and economic resources in coastal management and planning activities. The DPSIR method is here used taking into account processes and cause/effect relationship between Drivers and Pressures, which induce an alteration of actual State and, hence, Impacts on the environment, society and economy. The study area is located in South Italy (Apulia region), where the Risk Index is calculated and mapped for all municipalities facing the Adriatic and Ionian Seas. Both coastal Vulnerability and Exposure Indexes are firstly calculated according to the procedure suggested in the EUrosion project (EU model) as the product of specific indicators describing the state of coastal zones, their natural characteristics and both natural and anthropic pressures. Based on both EU model results and knowledge of states and pressures of the study area, a new modified model is then proposed (Mod.E.M.) and final risk maps compared. The comparison shows that new Vulnerability and Exposure indexes better describe the ongoing coastal processes and pressures and allow us to identify hot-spot sites where more detailed analyses could be further focused on. The Mod.E.M. has more than just a local significance since the case study includes coastal areas with so different characteristics, that it can be easily applied to other coastal regions. Moreover, to take into account climate change effects, Risk Index is evaluated under Representative Concentration Pathways $R C P 4.5$ and $R C P 8.5$, mainly affecting the sea level rise and the storm surge level.
\end{abstract}

Keywords: risk assessment; DPSIR; coastal erosion; coastal flooding; ICZM; EUrosion; climate changes

\section{Introduction}

Over the last decades, coastal risk assessment has become the first step in all strategic planning and management activities. Coastal areas are particularly exposed to risk drivers and are subject to a gradual weakening of the environmental asset, affecting also economic development and coastal community lifestyle (e.g., [1,2]). The growing urbanization and the massive exploitation are also threatening these areas, by reducing the resilience of territories after hazardous extreme events, exacerbated by climate change [3]. Moreover, the wide extension of coastal areas that must be protected requires economic investments that are often unsustainable for public administrations [4]. 
Hence, to support decision-makers in managing and prioritizing the interventions, the basic principles of the Integrated Coastal Zone Management (ICZM) have to be followed through the definition of a coastal Risk Index.

The analysis of critical environmental or safety situations is not only strictly related to the recognition of the physical processes driving erosion and flooding, but it depends primarily on characteristics of both natural and human environments and their interactions [5]. To create effective sustainable development policies, a correct balance between human, environmental, infrastructural, social and economic factors must be ensured, according to a cause-conditions-effect sequence, enabling a multidisciplinary and integrated vision of the overall environmental processes.

In the past years, several research projects aimed to assess coastal risk have been carried out and numerous approaches and GIS-based tools have been proposed, namely the DIVA model (DINAS-COAST project) [6] and the RVA method [7]. More recently, the THESEUS Decision Support System (DSS) [8], starting from an interdisciplinary approach, provided a coastal system status assessment exploiting an open-access approach. Moreover, the RISC-KIT project [9] proposed a two-step methodological approach in which a large scale Coastal Risk Assessment Framework (CRAF) is applied to detect coastal hot-spots where further in-depth higher resolution analyses are required.

Most of the risk assessment approaches are based on the Drivers-Pressures-State-Impact-Response (DPSIR) conceptual framework, that enables us to understand and explain the issues of actual or predicted situations and their potential evolution across different scales [10]. Indeed, through multivariate analysis, the DPSIR model can be used to examine mechanisms underlying environmental issues and interaction between society and environment [11]. The method is built on the selection of specific indicators, grouped by algorithms referring to a pyramid scheme of themes and objectives, aimed at framing the phenomenology under study.

A concise and reliable representation of processes underway can be only achieved if appropriate environmental indicators of the economic, social and environmental history of the study area and the connection patterns with potential hazards are known. Accordingly, over the years the DPSIR model has undergone significant transformations, mainly focused on deriving different definitions of States and Impacts, depending on the main aim of risk evaluation, available historical data and expert knowledge of processes and cause-effect relationships. Up to 2016, 25 versions of the DPSIR framework have been counted (e.g., [12-16]).

A significant research project funded by the European Union (EU) dealing with the risk assessment for the European coast based on DPSIR was introduced within the EUrosion project (www.eurosion. org). It follows a simplified DPSIR approach to map and classify coastal risk due to erosion and flooding at a regional scale, suggesting the use of specific parameters and indicators which are able to represent the state or a trend of coastal conditions.

In the present work, the DPSIR framework is used for assessing and mapping erosion and flooding risk in Apulia littoral (South Italy). Based on the analysis of both actual and past state of coastal territories, the risk profile is drawn for the study area to explain the relationship between causes and effects of the hazards affecting coasts. Consistently with EUrosion project guidelines, specific indicators are firstly used to quantify the Coastal Vulnerability Index (CVI) and the Coastal Exposure Index (CEI) and map the normalized Risk Index at a regional scale for all municipalities. Both CVI and CEI are then modified according to the risk profile. A Modified EUrosion Model (Mod.E.M.) is here proposed, involving different indicators and, for some indicators, integrating different variables. The main aim of the research is to develop a simple tool available for public administrations, useful to identify coastal hot spots at the regional scale and properly manage defense strategies priorities.

The paper is structured as follows. Section 2 recalls the models applied in the present work for quantifying the risk, according to the indicators and databases adopted. Section 3 briefly describes the study area, focusing the attention on natural and anthropogenic processes mainly responsible for the negative effects induced by flooding and erosion. According to the DPSIR framework, risk profile is defined for Drivers, Pressures, States and Impacts, specifically recognized in the Apulian 
coast. In Section 4 Vulnerability, Exposure and Risk maps derived from EUrosion and Mod.E.M. are compared and discussed. Conclusions on the adopted methodology for risk assessment at the regional scale and the risk level of Apulia coasts are finally drawn in Section 5.

\section{Risk Model}

\subsection{EUrosion Model}

The methodology proposed in the EUrosion project is one of the most popular models for coastal risk assessment widely used to map coastal hazard in the European littorals thanks to its simplicity and effectiveness $[17,18]$.

Risk Index (RI) (Equation (1)) is estimated as a product of coast predisposition to erosion and /or flood, termed as Coastal Vulnerability Index (CVI) and the exposure of the surrounding environment termed as Coastal Exposure Index (CEI). Since risk levels depend on the interaction of the two indicators, regions with low exposure and high vulnerability are considered low-risk. It has to be highlighted that in this paper, according to the latest terminology suggested by [2], the terms "Coastal Sensitivity" and "Coastal Vulnerability", originally used in EUrosion project, have been replaced, respectively, by "Coastal Vulnerability" and "Coastal Exposure".

$$
R I=C V I \times C E I
$$

In Table 1 both Vulnerability and Exposure indicators used by the EUrosion approach are reported, together with the relative score ranges.

Table 1. Ranking scores of CVI and CEI used in EUrosion (2004).

\begin{tabular}{lcccc}
\hline Coastal Vulnerability Indicators & \multicolumn{3}{c}{ SCORES } \\
& $\mathbf{0}$ & $\mathbf{1}$ & $\mathbf{2}$ \\
\hline SLR: Average speed of Sea Level Rise (mm/yr) & $<0$ & $0 \div 4$ & $>4$ \\
HWL: Highest water level (m) & $<1.5$ & $1.5 \div 3$ & $>3$ \\
TEV: Eroded or accreted shoreline (\%) & $<20$ & $20 \div 60$ & $>60$ \\
GEC: Coastal Geology- Rocky shoreline (\%) & $>70$ & $40 \div 70$ & $<40$ \\
ODC: Presence of coastal defence works (\%) & $<5$ & $5 \div 35$ & $>35$ \\
$A_{\text {RICE }}:$ Municipal area in RICE (\%) & $<5$ & $5 \div 10$ & $>10$ \\
\hline & & $5 C O R E S$ & \\
Coastal Exposure Indicators & 0 & 1 & 2 \\
\hline$U_{R I C E}:$ Urban and/or industrial area in RICE (\%) & $<10$ & $10 \div 40$ & $>40$ \\
$E_{R I C E}:$ High ecological value areas in RICE (\%) & $<5$ & $5 \div 30$ & $>30$ \\
$P_{\text {RICE }}:$ Resident population in RICE (1000 hab.) & $<5$ & $5 \div 20$ & $>20$ \\
$U_{10 \mathrm{~km}}:$ Increase in urban area in a 10 km wide coastal area (\%) & $<5$ & $5 \div 10$ & $>10$ \\
\hline
\end{tabular}

CVI represents morphological, geological and sediment characteristics of the study area, as well as wave energy approaching the coast, and CEI represents the level and class of human activities, infrastructures and socio-economic development. CVI and CEI values are calculated by the simple addition of the scores assigned to the selected indicators, while various index-based approaches have been proposed to assess coastal vulnerability by estimating the geometric mean of some selected indicators $[19,20]$. Over time, the Gornitz's CVI, probably the most popular index [21] has been greatly modified including multi-hazard and exposure indicators [7,22]. 
Pressure factors associated with Sea Level Rise (SLR) and storm surge combined with wave setup during particularly severe marine weather events (termed as Highest Water Level (HWL)) are the main cause of coastal flooding. Sea level data can be extracted from EUrosion project data-sets that cover the period 1985-2001. HWL analysis can be successfully integrated by using sea level data recorded from national and local tidal stations that provide continuous and reliable datasets. Coastal evolution trend (TEV) globally represents an index of beach dynamics. It considers both positive (accretion) and negative (erosion) shoreline movements, deemed as pressure factors that increase coastal risk. Coastal strip geology (GEC) allows estimating coastal potential exposure to erosion reflecting potential instability, through the analysis of geomorphology, by defining erodable (sandy and mixed sediment shores) and non-erodable (rock and cliffs) coast. Another pressure factor which, according to EUrosion, is the expression of coast instability and, hence, could contribute to increased risk level is the percentage of "engineered frontage" of the coast, due to the presence of protection structures (ODC). The last indicator considered in CVI evaluation identifies the coastal municipal area $\left(A_{R I C E}\right)$, corresponding to the percentage of municipal areas in the Radium of Influence of Coastal Erosion (RICE). The RICE area includes all areas potentially subject to erosion and flooding over the next 100 years, located within $500 \mathrm{~m}$ from the coastline and that can be extended to areas lying under $+5 \mathrm{~m}$ above sea level (a.s.l).

Impact factors are quantified by estimating the Coastal Exposure Index in the RICE, representative of coastal natural and anthropogenic value. Urban and industrial areas in the RICE $\left(U_{R I C E}\right)$ and their growth within $10 \mathrm{~km}$ from the shoreline $\left(U_{10 \mathrm{~km}}\right)$ have to be considered, as well as resident population $\left(P_{R I C E}\right)$ and high ecological value areas $\left(E_{\text {RICE }}\right)$.

\subsection{Modified EUrosion Model}

A critical analysis of the previous indicators has led to the development of the Modified EUrosion Model (Mod.E.M.) to better fit the local detailed Path of Effects (PoE). The path analysis allows us to describe the connection among the involved variables and are helpful in developing effective management plans to reduce the coastal risk [23]. The need for a risk map according to different sea-level rise scenarios (Flood Directive 2007/60/EC) has been taken into account in the proposed changes to include climate change effects.

Since risk assessment at regional scale requires a detailed analysis of local phenomena and site-specific metrics [24], the analysis is based on a preliminary study of causes leading erosion and flooding and the related effects on coastal zones, by means of the construction of the local PoE.

Hence, Coastal Vulnerability and Exposure Indexes are amended. The new indicators considered in the Mod.E.M. are presented in Equations (2) and (3), where: (i) starred indexes have the same meaning as in the EUrosion model but refer to different databases; (ii) new indicators are highlighted in bold; (iii) neglected indicators are strikethrough and (iv) normal font relates to the unchanged indicators.

$$
\begin{gathered}
C V I=S L R^{*}+H W L^{*}+A_{R I C E}+G E C+E S R L+H H_{R I C E}+\text { ODC }+ \text { TEV } \\
C E I=U_{R I C E}+E_{R I C E}+U_{10 K m}+P_{R I C E}^{*} .
\end{gathered}
$$

Climate-change-related flooding and erosion impacts are here considered by means of sea-level rise, not only due to stationary contributions of tides, waves and storm surges, but also considering extreme sea levels, thus affecting both SLR and HWL indicators. During the 21st century, according to the fifth Assessment Report (AR5) of Intergovernmental Panel on Climate Change [2], due to the climate changes affecting waves, storm surges and tides, the global mean sea level rise with medium confidence is expected to exceed the rate of the past 30 years with a rate of $8 \div 16 \mathrm{~mm} / \mathrm{yr}$, depending on the different long-term Representative Concentration Pathway (RCP) adopted scenario $(0.40[0.26 \div 0.55] \mathrm{m}$ for RCP2.6, $0.63[0.45 \div 0.82] \mathrm{m}$ for RCP8.5). 
To take into account even different scenarios, sea level rise projections (termed as RSLs inLISCoAsT database) are considered [25], under RCP4.5 and RCP8.5 scenarios, corresponding to a likely global mean temperature increase of $2.0-3.6^{\circ} \mathrm{C}$ and $3.2-5.4^{\circ} \mathrm{C}$ in $2081-2100$ above the $1850-1900$ levels. The LIScoast database also reports 100-year Extreme Storm Surge Levels (termed as ESSLs) estimated by means of the combined effect of tides and water level fluctuations due to waves and storm surges [26].

As reported in Equation (2), the shoreline evolution trend expressed by TEV indicator in EUrosion model is replaced by the new Eroded Shoreline indicator (ESRL) which only concerns with landward shoreline movements. It is evaluated by the weighted average of Past Shoreline Erosion (PSE) and Recent Shoreline Erosion (RSE) as follows:

$$
E S R L=0.3 P S E+0.7 R S E,
$$

where RSE and PSE are estimated from the eroded shoreline ratio assessed in the last 15 years and the previous decades, respectively. The ranking scores of RSE and PSE are reported in Table 2.

The analysis of PSE together with the RSE, helps to understand the long-term shoreline evolution trend and the most recent evolution. Analyzing only RSE could lead to a wrong interpretation of the process affecting the coast. Low RSE values indicate that negligible shoreline movements occur in the analyzed period. However, such an assumption could lead to misunderstanding the ongoing processes, since it could reveal a stability condition of the beach or, on the contrary, the full inhibition of the shoreline movement if the beach is completely eroded. Accordingly, the PSE helps us to understand the actual beach state, correlating it with its historical background.

Particular attention has to be paid in coastal erosion trend assessment, considering a temporal extent long enough to capture long-shore sediment dynamics neglecting extreme events and local dynamics. A threshold value for shoreline movement should also be applied to minimize errors resulting from operator digitization and exclude seasonal and/or tidal cycles from statistics.

Coastal areas flooding can be exacerbated when high river discharges and severe storm surges occur simultaneously since a storm can drive both high surges and river flows [27-29]. For this reason, to consider the further pressure induced by fluvial inundation on the coastal zone, the Hydraulic Hazard indicator $\left(H_{\text {RICE }}\right)$ is considered in the Mod.E.M. The new indicator can easily be estimated from the hydraulic hazard maps following the EC Flood Directive, calculated as the percentage of flooding-prone areas within the RICE.

The coastal protection structures indicator (ODC), considered in the EUrosion model, is neglected in the Mod.E.M. for regional risk assessment since a coastal structure could have different responses on the local scale, by increasing or reducing the sensitivity of the area against flooding and erosion. Such a morphodynamic response in presence of a coastal protection structure can be only quantified at the local scale, by means of numerical predictive calibrated models (e.g., [30-32]), able to reproduce hydrodynamics and morphodynamics induced by the presence of protection structures or harbors. EUrosion model considers also an indicator of the decrease in sediment supply from rivers, that has not been included in the discussion due to the major problems in collecting reliable riverine sediment transport data.

$P_{R I C E}^{*}$ indicator is quantified considering population data extracted from national census data-sets. In the present work, both tourists (seasonal population) and residents are considered since coastal areas host a large number of visitors that, in some municipalities, are more numerous than the residents.

The ecological value indicator $E_{R I C E}$ can be adequately estimated exploiting CORINE Land Cover data integrated with Natura 2000 and Regional Parks and Reserves maps. In many cases Natura 2000 areas include High Nature Value Farmland (HNVF) [33], hence, involving in the risk assessment also the exposure of agricultural areas.

Table 2 reports the new indicators considered in the present work and their relative weights. For the remaining indicators, the same scores and weights of EUrosion project are assumed. 
Table 2. Ranking scores of modified/added CVI indicators.

\begin{tabular}{lcccc}
\hline & \multicolumn{3}{c}{ SCORES } \\
Added Coastal Vulnerability Indicators & $\mathbf{0}$ & $\mathbf{1}$ & $\mathbf{2}$ \\
\hline PSE: Past shoreline erosion (\%) & $<20$ & $20 \div 60$ & $>60$ \\
RSE: Recent shoreline erosion (\%) & $<20$ & $20 \div 60$ & $>60$ \\
HH $_{\text {RICE }}$ : Hydraulic hazard in RICE (\%) & $<10$ & $10 \div 20$ & $>20$ \\
\hline
\end{tabular}

\section{Case Study}

\subsection{Description and Analysis of the Study Area}

The Apulia region is located in South Italy (East Mediterranean coast) and faces the Adriatic Sea in the North and East sides and the Ionian Sea in the South and West sides (Figure 1). The regional coastline is about $975 \mathrm{~km}$ long, with a large diversity of elevation and geological and morphological features (Figure 1). Sandy beaches and rocky coasts each represent about a third of the total, while high cliffs are $21 \%$ of the total coastline. Coastal cliffs are often characterized by caves, which worsen the effects of wave action, undermining cliffs stability and causing their collapse [34]. Shores of mixed sediments (including pebbly beaches) represent the $12 \%$ of the total shoreline.

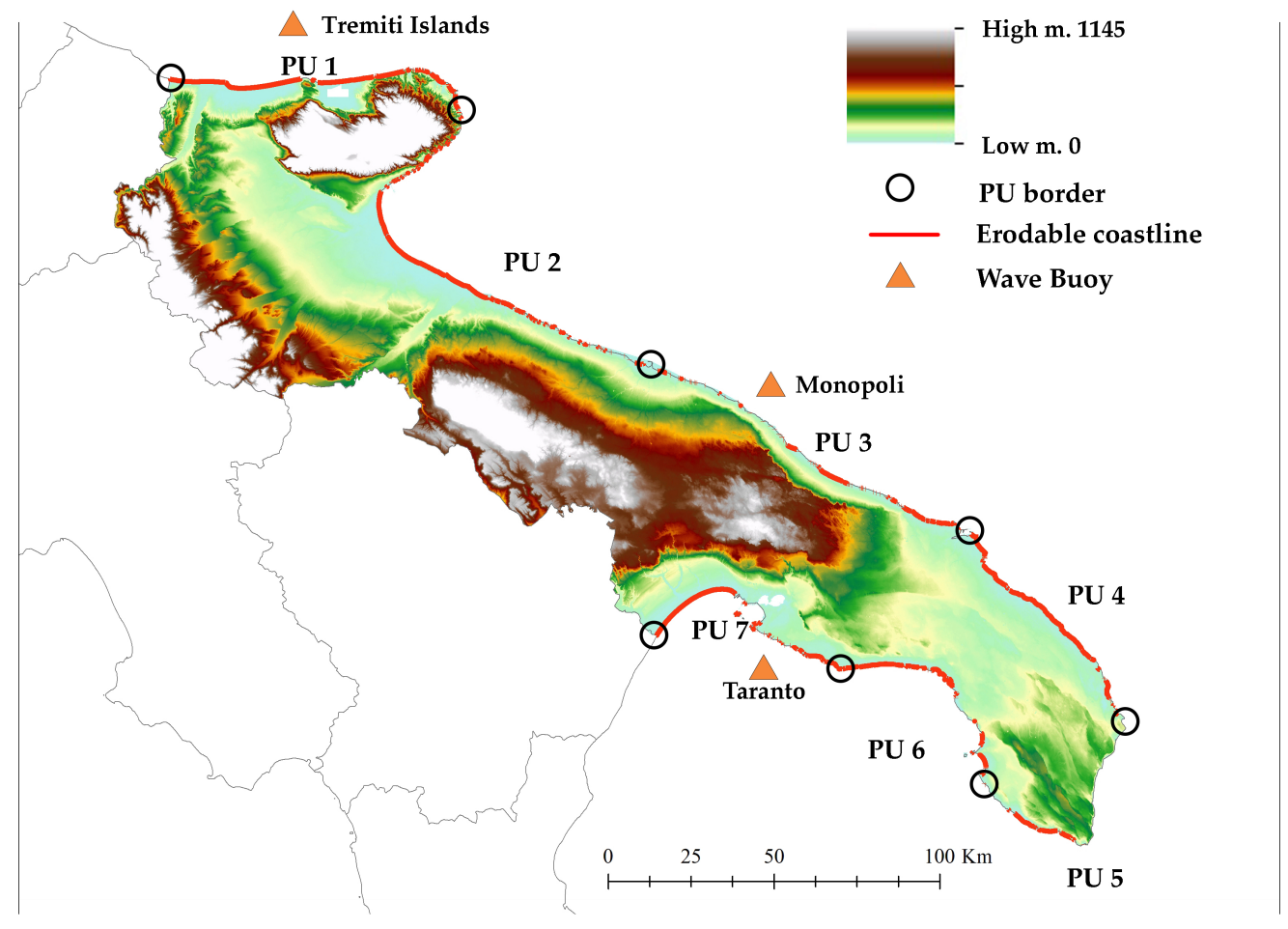

Figure 1. Study area: main Physiographic Units (white circles) and erodable coastline (red lines). Wave buoy location is also reported (orange triangles).The Digital Elevation Model is from http: //www.sit.puglia.it/.

On the regional coastline, seven main Physiographic Units (PU) are identified (Figure 1). Each PU is a very complex environment and several types of coastline can be found: (i) long sandy beaches bordered by coastal dunes (PU1, PU4, PU7), (ii) beach barriers that separate coastal lagoons from the open sea (PU1, PU5), (iii) low-lying areas with long sandy beach (PU2), (iv) pocket beaches (in almost all the PU), (v) sea cliffs and rock coastlines (with or without protective beach) (PU1, PU3, PU5, PU6). 
Wave climate analysis is based on data collected offshore Taranto and Tremiti Islands by the Apulia Region Meteomarine Network (http:/ /93.51.158.171/web/simop/home) and offshore Monopoli by the Italian Wave Network (IWN) as reported in Figure 1. The distribution of the percentage frequency of wave direction and height in the selected locations (Figure 2) shows that the wave climate is moderate, characterized by low-medium energy sea states [35-37]. While extreme wave storm events are not very frequent, Apulian coasts are subject to considerable phenomena of coastal erosion and flooding, which lead to negative consequences on both natural and anthropic environmental as well as human life.

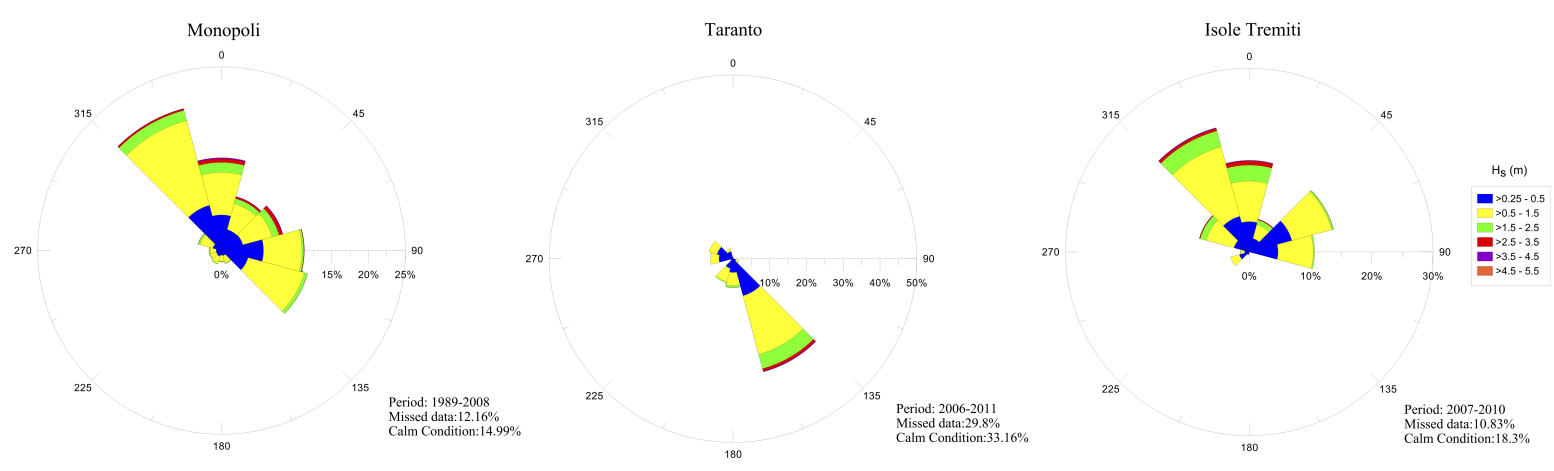

Figure 2. Wave roses estimated from the wave timeseries collected offshore Tremiti Islands, Monopoli and Taranto.

In the early twentieth century, the realization of coastal railway lines and road system and the massive reclamation of wetlands started the initial transformation of coastline with a relevant erosion of most sandy beaches. Then, in the second half, the growth of tourism increased the demand for land in coastal areas to be used for tourist facilities. Nowadays, the Apulia region enjoys a growing reputation both on the national and international tourism markets. It is identified as a high nature value destination and sea and protected natural areas constitute the main environmental resources attracting thousands of tourists every year. In this regard, the highest priority of regional policy is to enhance natural, cultural and landscape regional resources to increase its attractiveness, without deteriorating natural environment. It follows that a further increase in tourist flows must necessarily be associated with forward-looking management of coastal territories, based on protection and recovery strategies aimed at preserving landscape and environment, and on the improvement of infrastructures and tourism services.

The regional hydrographic network is rather poor and mainly endorheic. Highly permeable soils inhibit the sediment movement through surface runoff and sediment trapping by dams and river regulation works contributes to extensive losses of wetlands and deltas, reducing watershed sediment input to the coastal sand budget [38]. Moreover, low-lying or depressed area, which constitutes a significant portion of regional coastal territories, are often subjected to flooding during storm events even not particularly intense $[29,39]$.

Coastline evolution has been also strongly influenced by the gradual disappearance of dunes belts, which act as a sediment reservoir and a protection system for the back dune areas [40]. All these pressures led to a progressive deterioration of the physical environment with negative effects on the economy [41].

The above conditions forced local administrations to carry out an extensive campaign of beach monitoring [42-45], protection and restoration interventions [46], testing also alternative strategies [47], since the coastal protection strategies often prove to be not adequate to counteract the erosive action of waves, the reduction of sediments supply and flooding events.

From an administrative point of view, the regional coastline falls within the planning jurisdiction of 68 municipalities, some with constrained access, and this is a measure of management and planning fragmentation. Hence, following the principles outlined in ICZM, in 2007 Apulia region drafted and 
implemented the Regional Coastal Plan (PRC) [48], which still constitutes a useful regulatory and technical operational tool intended to standardize coastal areas protection and maintenance. The plan aimed at defining the status of the Apulian coast as well as to identify the most critical and sensitive (from an environmental and historical point of view) coastal zones [49]. Significant efforts were focussed on collecting large geospatial datasets that are regularly updated (http:/ /www.sit.puglia.it/).

\subsection{Risk Profile}

According to the above characterization of Apulian coasts, processes are summarized through the Path of Effects (PoE), defined as a cause-effects chain, where processes are categorized in Drivers, Pressures and the corresponding States and Impacts (e.g., [23]). Figure 3 shows the path of risk flow chart developed for the presented case of study. Since differences in terminology and definitions in the DPSIR model could lead to a misunderstanding and ambiguities in the interpretation of results (e.g., $[12,16,50])$, a declaration of the adopted terms is required. In the present work, a risk profile is drawn by starting from the identification of the main drivers of erosion and flooding hazards typically considered in coastal risk assessment. Two main groups of drivers are defined (considered relevant) for the hazard characterization. The first group (anthropogenic) involves basic human needs-related drivers occurring with social and economic development. Human activities and policies aimed at satisfying such needs lead human-induced pressures on the coastal environment. The second group includes physical drivers exerted by natural phenomena, combining sea storms and meteorological events (e.g., precipitation) with climate change. The latter, even if actually derived from long-term effects of human existence, are here recognized as exogenous drivers, as they increase the magnitude and frequency of coastal storms, extreme discharges and considered as the main cause of sea level rise.

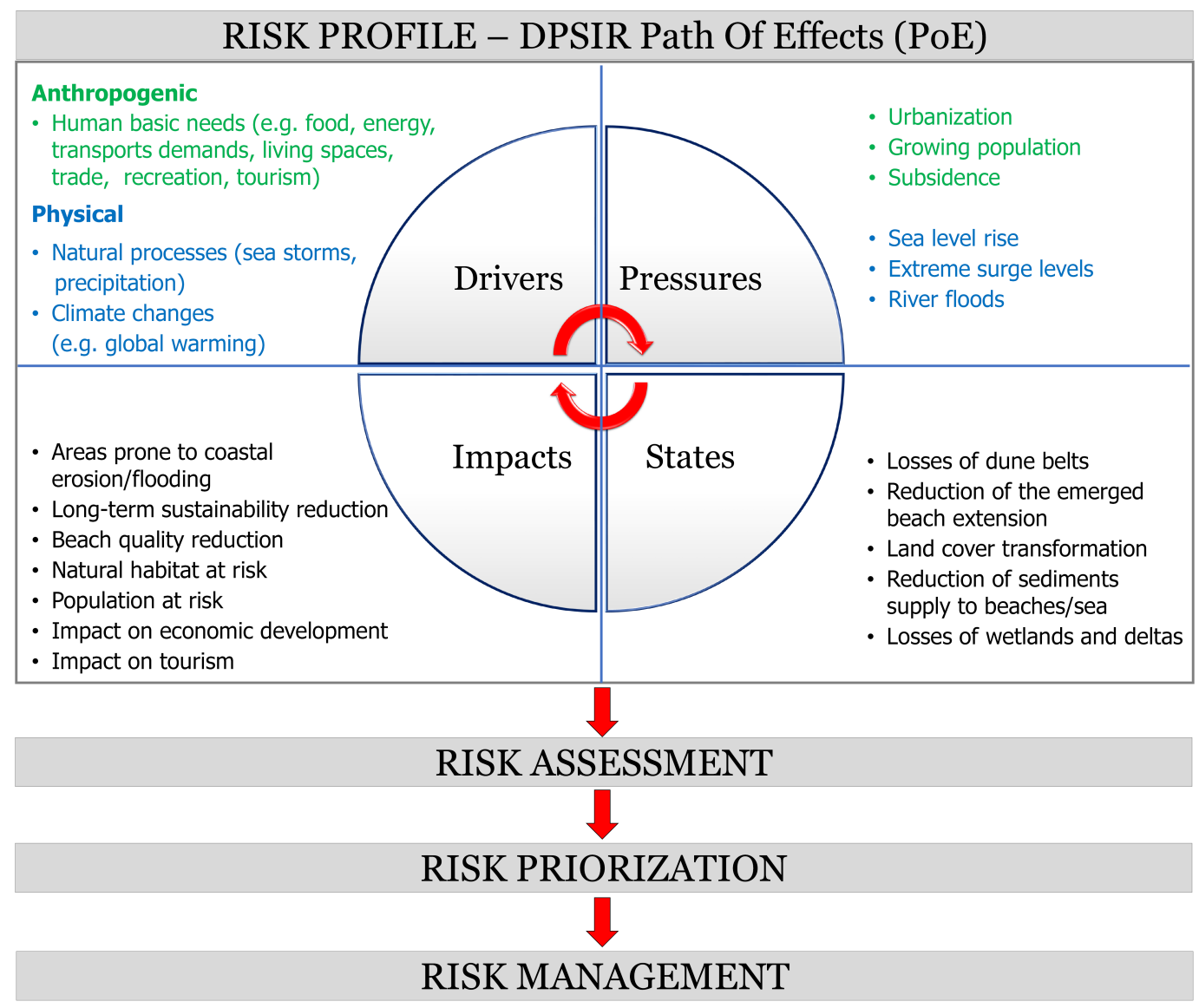

Figure 3. Path of Effects (PoE)-based risk assessment flow-chart. 
The relative pressures are strictly related to the processes responsible for coastal erosion and flooding, resulting from both anthropogenic and physical drivers. Urbanization, growing population and subsidence are the negative pressures induced by social and economic development of coastal zones and their heavy exploitation. Extreme surge levels, sea level rise and river floods are here considered as the pressures induced by physical drivers, exacerbated by the effects of climate changes. Consequently, changes in coastal environment states result in impacts on human health, ecosystems and economy. It has to be stressed that in the Figure 3 quantitative/qualitative changes of States are reported. Negative consequences are associated with alteration of sediment budget balance, losses of dune belts, reduction of the emerged beach extension, land cover transformation and losses of wetlands and deltas. Impacts, in turn, affect drivers and exacerbate the process. Hence, decisive responses are required to prevent negative impacts and preclude additional pressures. In such a way, potentially damaging events can be proactively managed by means of contrasting adaptation measures.

\subsubsection{CVI indicators}

In the following analyses, the extent of the RICE area has a minimum width of $500 \mathrm{~m}$ extended to coastal areas below $5 \mathrm{~m}$ a.s.l. to expand risk analysis to low-lying areas.

The analysis of the $A_{\text {RICE }}$ indicator shows that several coastal zones, mostly located in PU2 and PU7 (Figure 1), are prone to coastal flooding due to the natural conformation of the most inland territories, characterized by very low depths above the mean sea level. Some of those low-lying zones are flooded even during ordinary sea storms, giving some areas a typical lagoon appearance with considerable damage to both productive and touristic sites.

Compared to other coastal European countries, in the Apulia region, both SLR and HWL indexes are constant and relatively low (Table 3). According to [2] offshore the Apulian coast, compared to the period 1986-2005, the mean sea level is expected to rise for 2081-2100 about $35 \mathrm{~cm}$ (RPC2.6). $H W L_{100}$, obtained by combining the projections of astronomical tides and the 100-year meteorological tide (storm surge and wave setup), has been extracted from LISCoast database [25]. Present-day $H W L_{100}$ values show a good agreement with other available datasets (e.g., EUrosion [11]) and values estimated carrying out the analysis of extreme sea levels and tidal residuals recorded by the Apulia Region Meteomarine Network and the Italian National Tide Gauge Network [39,51]. Nevertheless, due to the limitations of the spatial and temporal scale in the ocean modeling [26], local surge and wave prediction are required at smaller scale risk assessments.

According to to [26], the mean sea level is expected to increase around $45 \mathrm{~cm}$ on average for Apulia by 2100 under RCP4.5 and about $70 \mathrm{~cm}$ under RCP8.5 (Table 3). While $H W L_{100}$ shows a very slight increase by 2100 since, as observed by [26], rising total extreme sea levels are mainly due to sea-level rise because of the bigger effect of climate change on RSLR than on extreme meteorologic events.

Table 3. Median present-day 100-year HWL $\left(H W L_{100}\right)$ and projected sea level rise; SRL and $H W L_{100}$ under RCP4.5 and RCP4.5 by 2110 . Values extracted from the LISCoast database have been averaged in each Physiographic Unit (PU).

\begin{tabular}{ccccccc}
\hline & \multicolumn{2}{c}{ Present Day } & \multicolumn{2}{c}{ RCP45 } & \multicolumn{2}{c}{ RCP85 } \\
\hline PU & SRL $(\mathbf{m})$ & HW $_{\mathbf{1 0 0}}(\mathbf{m})$ & SRL $(\mathbf{m})$ & HW $_{\mathbf{1 0 0}}(\mathbf{m})$ & SRL $(\mathbf{m})$ & HW $_{\mathbf{1 0 0}}(\mathbf{m})$ \\
\hline PU1 & 0.35 & 1.0 & 0.44 & 1.1 & 0.72 & 1.1 \\
PU2 & 0.35 & 0.9 & 0.45 & 1.0 & 0.72 & 1.0 \\
PU3 & 0.35 & 1.0 & 0.46 & 1.1 & 0.72 & 1.1 \\
PU4 & 0.35 & 1.0 & 0.46 & 1.1 & 0.72 & 1.1 \\
PU5 & 0.35 & 1.1 & 0.46 & 1.2 & 0.72 & 1.2 \\
PU6 & 0.35 & 1.1 & 0.47 & 1.2 & 0.76 & 1.2 \\
PU7 & 0.35 & 1.0 & 0.47 & 1.1 & 0.75 & 1.1 \\
\hline
\end{tabular}


The $H H_{R I C E}$ indicator is estimated exploiting the official flooding areas mapped in the Hydro-Geologic Safety Plan produced by the Apulian basin authority [52]. In the Apulian coastal region, high-risk river flooding areas can be observed in PU2 and PU7.

Passive and active remote sensing techniques are an essential element in the early identification of critical areas [40,49,53,54], since extensive in situ campaigns are too cost- and time-expensive in wide areas. Aerial images taken in 1992, 2005 and 2017 are used for the aim. A polygon overlay analysis is used to determine areas where shoreline deviation is greater than $10 \mathrm{~m}$ and shoreline evolution trend (TEV) is estimated. The TEV analysis shows significant erosive phenomena in the Apulian coastline: the evolution analysis in the period 2005-2017 (Table 4) reveals that about $34 \%$ of sandy coast $(127 \mathrm{~km})$ suffered from erosion processes. Further analyses carried out by exploiting orthophotos taken in 2008, 2010 and 2011 highlight that sandy coasts suffered a sharp and sudden deterioration between 2008 and 2010 , leading to the erosion of about $31 \%$ of the total coastline.

The coastal erosion of the Apulian coastline is certainly not a recent phenomenon, since $130 \mathrm{~km}$ of sandy coastline receded over the period 1960-1992 (Table 4). The last analysis is carried out superimposing the IGMI cartographic maps (scale 1:25,000) dated back to 1960 with the 1992 coastline and determining only areas where shoreline deviations were greater than $30 \mathrm{~m}$ to take in account geolocation and large-scale map accuracy. Whereas in the period between 1992 and 2005 erosive phenomena affected only the $16 \%$ of sandy coast $(63 \mathrm{~km})$. The erosive processes are expanding not only to previously eroded areas but new critical areas are emerging in the entire regional coastline. Moreover, it has to be highlighted that in many cases the trend evolution has been limited by the presence of coastal protection structures that prevent shoreline recession and irreversible coastline changes.

Table 4. Shoreline change rates in the periods 1960-1992, 1992-2005 and 2005-2017.

\begin{tabular}{cccccc}
\hline & $\begin{array}{c}\text { Sandy Shoreline } \\
(\mathbf{k m})\end{array}$ & $\begin{array}{c}\text { Average Width } \\
\mathbf{( m )}\end{array}$ & $\begin{array}{c}\text { Erosion 1960-1992 } \\
\mathbf{( \% )}\end{array}$ & $\begin{array}{c}\text { Erosion 1992-2005 } \\
\mathbf{( \% )}\end{array}$ & $\begin{array}{c}\text { Erosion 2005-2017 } \\
\mathbf{( \% )}\end{array}$ \\
\hline PU1 & 81.9 & 30.6 & 21.0 & 22.3 & 39.6 \\
PU2 & 77.9 & 29.9 & 32.5 & 28.0 & 31.9 \\
PU3 & 36.3 & 18.4 & 55.4 & 3.2 & 43.2 \\
PU4 & 62.8 & 19.8 & 64.9 & 23.9 & 31.9 \\
PU5 & 18.7 & 23.3 & 19.2 & 16.1 & 45.3 \\
PU6 & 42.1 & 20.4 & 25.8 & 4.3 & 22.9 \\
PU7 & 46.5 & 29.6 & 26.5 & 2.3 & 25.3 \\
Total & 366.2 & 25.5 & 35.5 & 16.2 & 33.2 \\
\hline
\end{tabular}

Information on both coastal geomorphology (GEC) and coastal protection structures (ODC) is achieved by further detailing and updating up to 2017 the data used for the Apulian Regional Coastal Plan [48]. Coastal areas with a high percentage of engineered coastline are located in the Gulf of Manfredonia (PU2), where almost 55\% of the coastal protection works were placed to counteract and mitigate severe erosion processes affecting the area. However, except the above-mentioned area and those municipalities that host important port activities, the regional coastline evolution seems to be little affected by coastal protection structures.

\subsubsection{CEI Indicators}

Impacts are then quantified by estimating the CEI representative of coastal natural and anthropogenic assets, derived from CORINE Land Cover (CLC) soil maps 1990, 2000, 2012 and 2018. Both land use analysis $\left(U_{R I C E}\right)$ and land-use change over 1990-2018 in a $10 \mathrm{~km}$ wide coastal area $\left(U_{10 \mathrm{~km}}\right)$ show a significant and growing urbanization in the Apulian coastline with a consequent increased demographic concentration $\left(P_{\text {RICE }}\right)$. The evaluation of $U_{10 \mathrm{~km}}$ over two different periods (1990-2018 and 2006-2018) shows that for most of the examined municipalities, the increasing trend has been reduced in the second decade, especially for those areas facing the Ionian Sea. On the other hand, an increase of urban/industrial areas involves some of the most important urban centers and towns 
with a strong tourist vocation. Over the last decades, due to the expansion of industrial/commercial areas, together with high population density, regional coastal areas have suffered a major loss of natural areas and habitats that serve as buffer zones between the sea and the hinterland, resulting in a coastal squeeze.

$P_{R I C E}$ indicator is estimated exploiting the data collected by the Italian National Statistical Institute (ISTAT) for years 1991, 2001 and 2011. Among the population data, the touristic population is also considered, since in the last years an increase of seasonal population occurred. ERICE indicator is derived from CORINE Land Cover used datasets integrated with Natura 2000 and Regional Parks and Reserves maps. In the Apulia region, the network of protected areas, established under the EU Birds and Habitats Directives, occupies $21 \%$ of the regional area. It should be also emphasized that a large percentage of Natura 2000 areas in Apulia region includes High Nature Value Farmland (HNVF) [33] allowing to include in the risk assessment also the exposure of agricultural areas. In Table 5 the databases used in the present work are reported.

Table 5. Reference database of CVI and CEI indicators.

\begin{tabular}{ll}
\hline Indicator & Data Source \\
\hline SLR & EUrosion (2006); IPCC (2013); LISCoAsT (2018) \\
HWL & EUrosion (2006); Bruno et al. (2014); LISCoAsT (2016) \\
TEV & Aerial photographs (1992, 2005, 2017) \\
PSE & Historic maps, aerial photographs (1960) \\
GEC & RCP (2005); Regional hydro-morphological map (2012) \\
$A_{R I C E}$ & Hydro-morphological map (2012) \\
HH $H_{R I C E}$ & PAI Apulian Region Basin Authority (2005) \\
ODC & R.C.P. (2005); Regional hydromorphological map (2012) \\
$P_{R I C E}$ & ISTAT (1991, 2001, 2011) \\
$U_{R I C E}$ & CORINE Land Cover CLC (1990, 2000, 2012, 2018) \\
$E_{R I C E}$ & CLC (1990, 2000, 2012, 2018); Natura 2000 Network, Regional Parks and reserves \\
$U_{10 \mathrm{~km}}$ & CLC (1990, 2000, 2012, 2018) \\
\hline
\end{tabular}

\section{Results and Discussion}

\subsection{CVI and CEI Indicators}

The quantification of the CVI and CEI indicators is performed for all coastal regional municipalities. Both vulnerability and exposure indexes are represented through a color map (Figure 4) that easily allows identifying causes and impacts on the regional coastline at the municipality scale. With respect to Figure 4, it can be seen that the highest scores in GEC and ESRL indicators are present in PU1, PU2, PU3 and PU7, where the greater concentration of population $\left(U_{R I C E}\right.$ and $P_{R I C E}$ can be seen in PU2 and PU3. The $A_{R I C E}$ indicator reaches the high or medium score in almost all the municipalities, while the highest scores in $H_{\text {RICE }}$ can be found in PU2 and PU7.

CVI and CEI under RCP4.5 and RCP 8.5 conditions are not reported in Figure 4, since only a variation in SWL score occurs. Climate change, according to [26], seems to affect only sea-level rise rather than storm surge levels. 


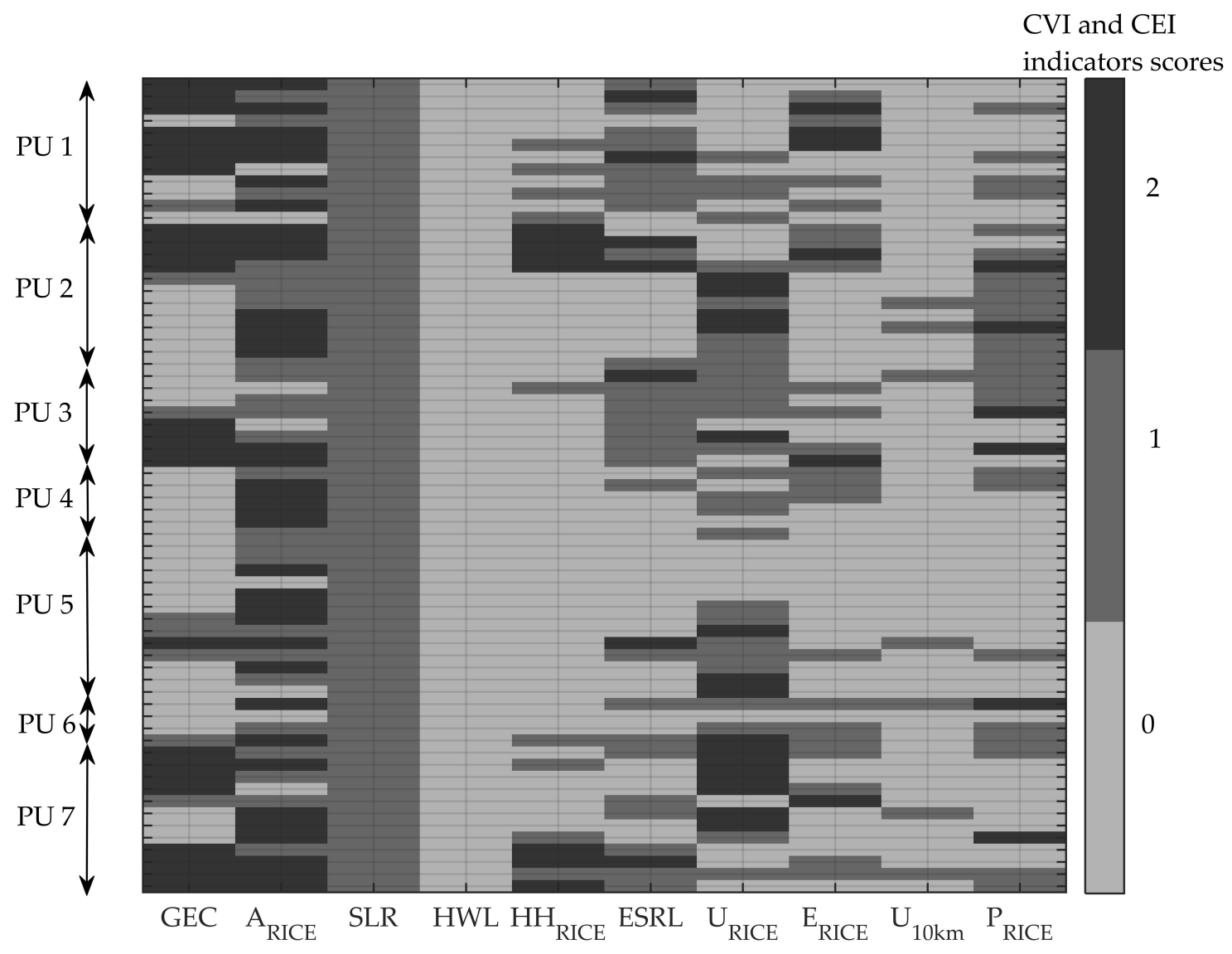

Figure 4. Scores calculated for CVI and CEI indicators in all municipalities.

\subsection{Risk Levels}

Risk levels have been mapped at a regional scale with levels normalized with respect the maximum value theoretically derived from the model, according to the EUrosion procedure (Figure 5a). Accordingly, 5 classes of risk are identified: (i) very low, 0-5 (ii) low, 5-15 (iii) medium, 15-30 (iv) high, 30-50 (v) very high, 50-100.

Since the presence of coastal protection structures and harbors should not be considered a priori as a pressure variable, according to the discussion presented in Section 2, the indicator ODC has been neglected in the EUrosion model.

Figure 5a does not highlight significant risk situations, reaching medium and low values, if compared to the risk levels observed in the most stressed coastal areas in Europe (e.g., [11]) and in the Northern Adriatic Sea in Italy (e.g., $[7,17,55])$. However, about $27 \%$ of the regional coastline presents a medium risk level. Two coastal hot spots are highlighted in the Gulf of Manfredonia (PU2), where the predominant risk factors are essentially due to the coastal type, characterized by long sandy coastlines and low inland heights, the erosion rates and the presence of high ecological value areas. Other critical areas can be detected in the regional coastline, especially the major cities and the most known touristic areas where coastal exposure has larger values. In Figure $5 b$ the normalized risk indicator (nRI) derived from the Mod.E.M. is mapped for the regional coastline, using the present-day values. The comparison between the two models (Figure 5a,b) shows that both the new indicators and data-sets considered in the present work affect RI calculation. With reference to Mod.E.M. results, an increase of risk level can be observed, mainly due to the $H_{\text {RICE }}$ indicator and seasonal tourist population considered in $P_{\text {RICE }}$, since they increase both CVI and CEI. Almost $25 \%$ of the municipalities are affected by river flooding in the coastal area and these events cannot be overlooked since heavy rainfalls are increasingly driven by changing climate [2]. This aspect can be better appreciated by looking at Figure 6, where land cover, 
shoreline erosion and river flooding areas are mapped in a region within PU2. The highlighted area is chosen because it contains several important aspects: (i) it has been heavily affected by erosion since the second half of the 20th century and the shoreline retreat is currently ongoing, (ii) a large part of that area is covered by the largest saltworks in Europe and it is classified as a protected natural area and (iii) wide flood-prone areas have been identified by [52]. In such a context the EUrosion procedures highly underestimate the coastal vulnerability and exposure.

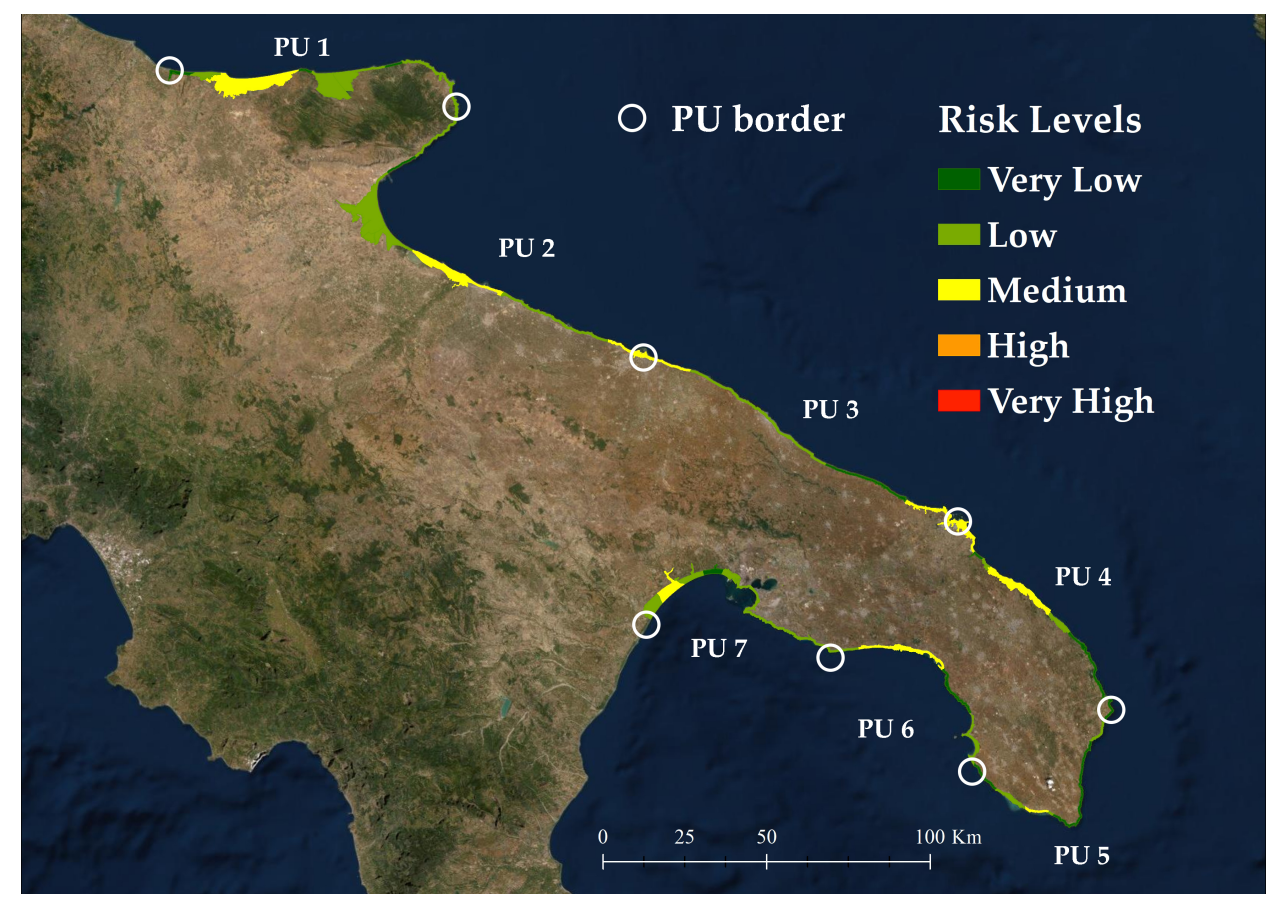

(a)

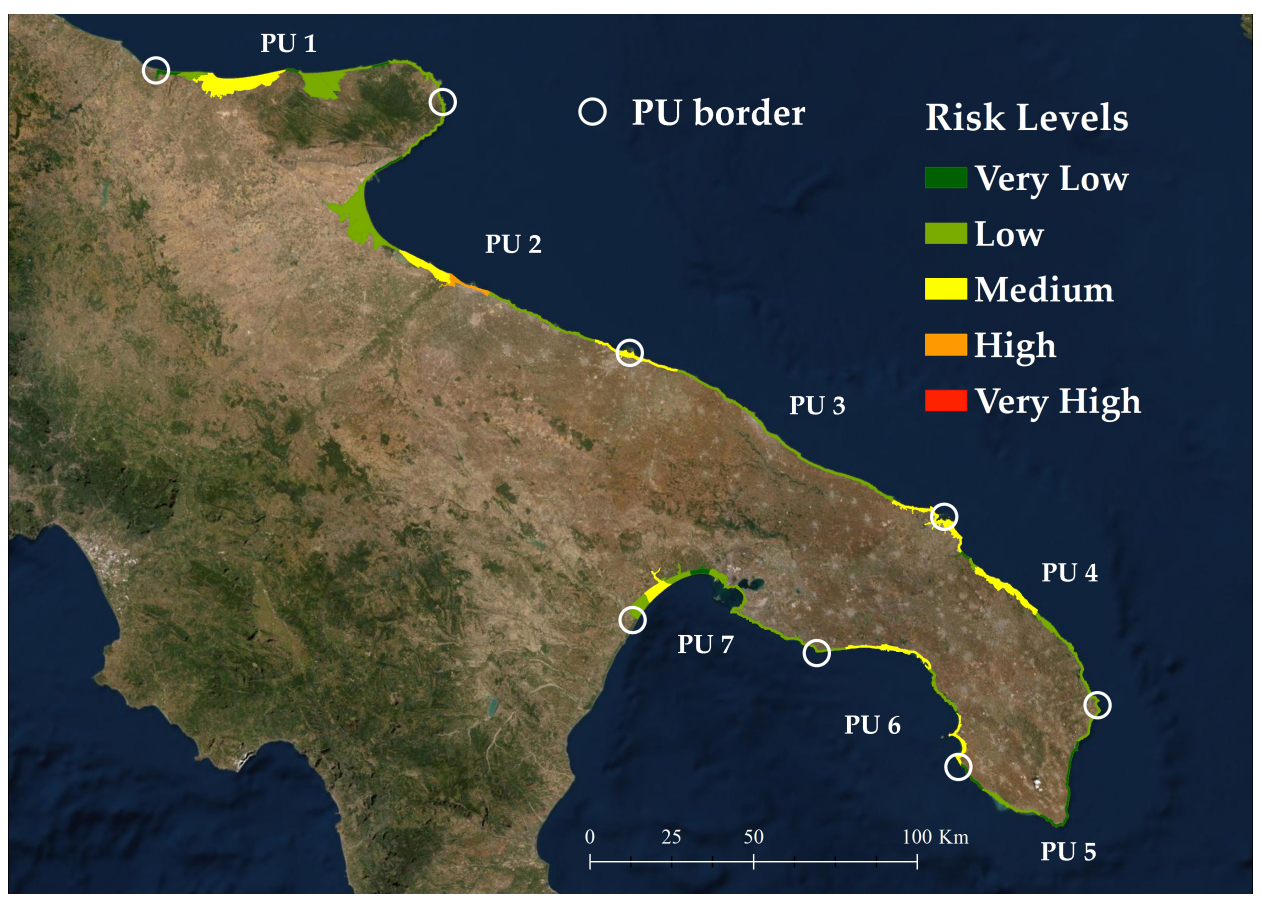

(b)

Figure 5. Normalized Risk Levels for all Apulian municipalities estimated using: (a) EUrosion model; (b) modified EUrosion model: present-day values. The satellite image is from GoogleEarth. 


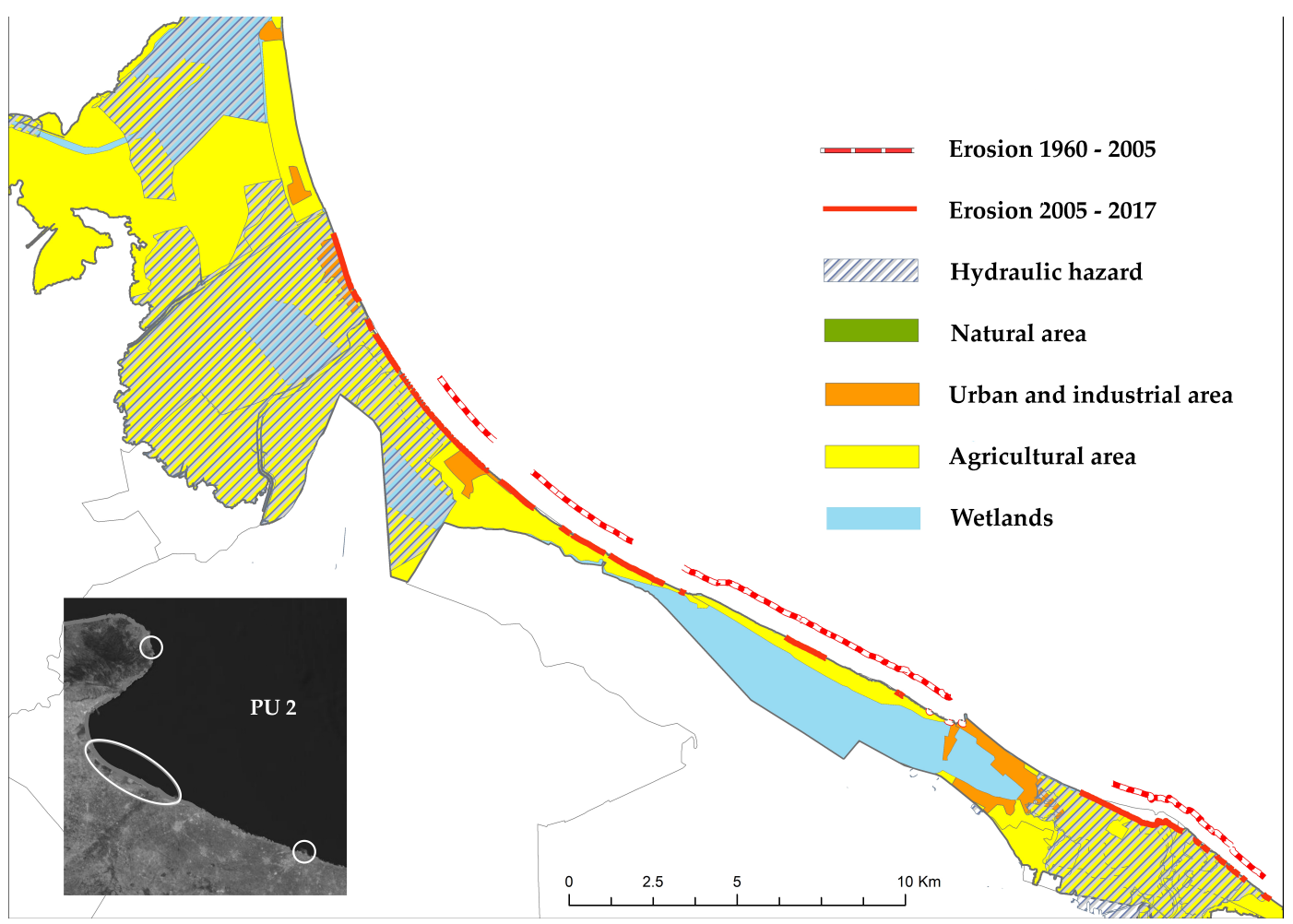

Figure 6. Land cover, shoreline erosion and river flooding areas in a selected area within PU2.

The inclusion of the seasonal population leads to an increase of the $P_{R I C E}$ for $30 \%$ of the coastline, highlighting the high tourist pressures on the exposed population and coastal facilities. On the contrary, the new indicator ESRL which takes into account both past and recent shoreline erosion are reduced with respect to TEV for about $7 \%$ of the shoreline since beach accretion is not considered, whereas a small increase in ESRL has been estimated for about $7 \%$ of the shoreline.

The validation of risk assessment models remains a challenge in multi-hazard environments such as coastal areas $[18,55]$, therefore estimated risk levels have been compared to publicly available information (e.g., Civil Protection bulletins and local news) and in-situ survey campaigns after severe weather events $[29,40,56]$. Obtained results demonstrate that the proposed Mod.E.M is able to reproduce the coastal situation more closely to reality, introducing new pressures that cannot be neglected in the study area, considered as a benchmark in the present work, and deleting indicators that cannot be included without a detailed local analysis.

The changes made on the indicators stem from a case study that covers so wide coastal regions, including different main Physiographic Units, that the use of new indicators can be easily extended in different territorial contexts. On the other hand, the suggested modifications don't increase the number of indicators since a good index for risk assessment should be easily applicable and avoid overlapping among the various indicators $[7,22,57]$.

Figure 7 reports the risk map under the RCP4.5 scenario. Under RCP4.5 (Figure 7), the LISCoast projection datasets relative to sea level rise induce an expected increase of CVI overall coastal municipalities, since SLR assume higher values, reaching the maximum score, while HWL score remains low. Low-risk shoreline ratio decreases from $60 \%$ to $40 \%$ passing from present-day values to the RCP4.5 scenario, whereas the medium risk shoreline ratio increases from $26 \%$ to more than $38 \%$ (Figure 8). In the worst scenarios, about $14 \%$ of the regional shoreline becomes a "high risk" area. No changes between RCP4.5 and RCP8.5 scenario are observed since the expected sea-level rise by 2100 reaches the maximum score already in the RCP4.5 scenario and climate change does not affect HWL scores [26]. 


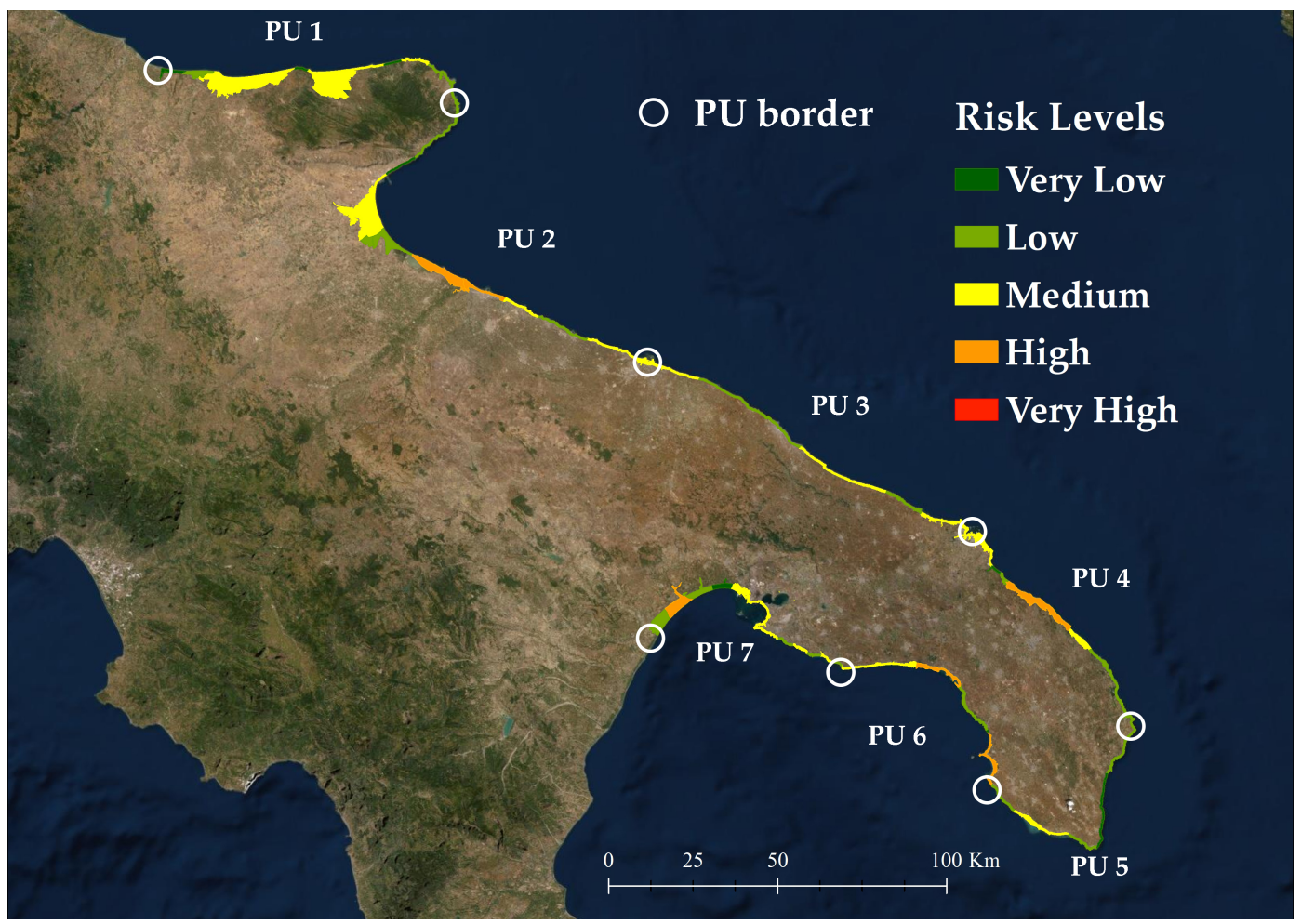

Figure 7. Normalized Coastal Risk Levels estimated using the modified EUrosion model: Scenario IPCC RCP4.5. The satellite image is from GoogleEarth.

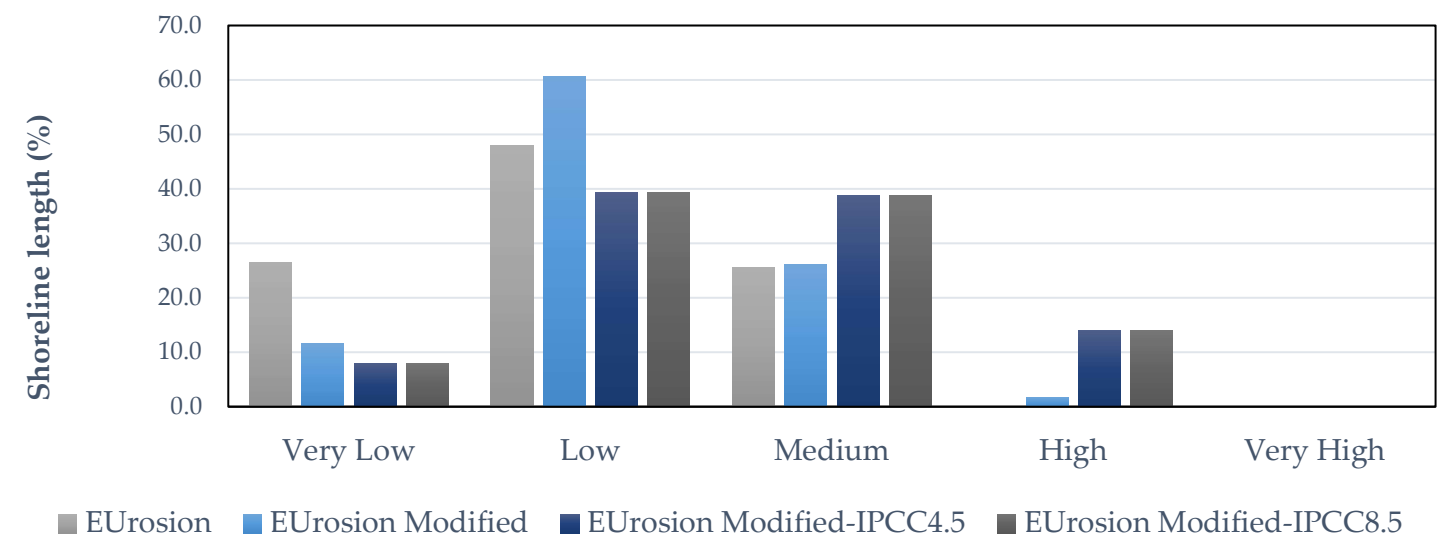

Figure 8. Comparison of results obtained using different approaches and scenarios.

\section{Conclusions}

The DPSIR model is used here for defining a risk map at the municipal scale to identify coastal areas more exposed to erosion and flooding risk. In this paper, a Modified Eurosion Model (Mod.E.M.) is proposed to map coastal risk at a municipal scale and identify coastal hot-spots. It can be used for rating coastal regions in terms of exposure to coastal erosion and flooding and it is useful for the management and planning of coastal areas.

The Mod.E.M. is here used to map the Risk Index for Apulia coastal areas (South Italy). The new indicators have been proposed after a critical discussion of the original indicators based on the local PoE analysis. Compared to the original EUrosion model, it has to be highlighted the importance to include indicators that also consider past erosive processes, river flood hazards and seasonal population. Since the case study includes coastal areas with different characteristics, the improved model can be easily applied to other coastal regions and it has more than just a local significance. Moreover, climate 
change scenarios show an increase in the number of coastal hot-spots in the region requiring further analysis. The Mod.E.M. has the advantage of exploiting public data without the need for numerical modeling. Once the coastal hot spots are identified, more in-depth studies are needed to understand the occurring phenomena, by means of more detailed data (also not of public domain), in-situ surveys and monitoring programs, supported by suitable numerical as well as physical modelling.

Author Contributions: All authors contributed in equal measure to all stages of the development and production of this paper. All authors have read and agreed to the published version of the manuscript.

Funding: The present study is part of the STIMARE project, funded by the Italian Ministry for the Environment and Protection of the Territory and the Sea-C.U.P. J56C18001240001.

Conflicts of Interest: The authors declare no conflict of interest.

\section{References}

1. Nicholls, R.J.; Wong, P.P.; Burkett, V.; Codignotto, J.; Hay, J.; McLean, R.; Ragoonaden, S.; Woodroffe, C.D.; Abuodha, P.; Arblaster, J.; et al. Climate Change 2007: Impacts, Adaptation, and Vulnerability. Part A: Global and Sectoral Aspects. Contribution of Working Group II to the Forth Assessment Report of the Intergovernmental Panel on Climate Change; Cambridge University Press: Cambridge, UK, 2007.

2. IPCC. Climate Change 2014: Synthesis Report. Contribution of Working Groups I, II and III to the Fifth Assessment Report of the Intergovernmental Panel on Climate Change; Core Writing Team, Pachauri, R.K., Meyer, L.A., Eds.; IPCC: Geneva, Switzerland, 2014.

3. Nicholls, R.J.; Woodroffe, C.; Burkett, V. Chapter 20-Coastline Degradation as an Indicator of Global Change. In Climate Change, 2nd ed.; Letcher, T.M., Ed.; Elsevier: Boston, MA, USA, 2016; pp. 309-324.

4. Pranzini, E.; Williams, A.T. Coastal Erosion and Protection in Europe; Routledge: New York, NY, USA, 2013.

5. Archetti, R.; Damiani, L.; Bianchini, A.; Romagnoli, C.; Abbiati, M.; Addona, F.; Airoldi, L.; Cantelli, L.; Gaeta, M.G.; Guerrero, M.; et al. Innovative strategies, monitoring and analysis of the coastal erosion risk: The STIMARE project. In Proceedings of the 29th International Ocean and Polar Engineering Conference, Honolulu, HI, USA, 16-21 June 2019; International Society of Offshore and Polar Engineers: Mountain View, CA, USA, 2019.

6. Hinkel, J.; Klein, R.J. Integrating knowledge to assess coastal vulnerability to sea-level rise: The development of the DIVA tool. Glob. Environ. Chang. 2009, 19, 384-395. [CrossRef]

7. Torresan, S.; Critto, A.; Rizzi, J.; Marcomini, A.; Mendez, F.; Leschka, S.; Fraile-Jurado, P. Assessment of coastal vulnerability to climate change hazards at the regional scale: The case study of the North Adriatic Sea. Nat. Hazards Earth Syst. Sci. 2012, 12, 2347-2368. [CrossRef]

8. Zanuttigh, B.; Simcic, D.; Bagli, S.; Bozzeda, F.; Pietrantoni, L.; Zagonari, F.; Hoggart, S.; Nicholls, R.J. THESEUS decision support system for coastal risk management. Coast. Eng. 2014, 87, 218-239. [CrossRef]

9. Van Dongeren, A.; Ciavola, P.; Martinez, G.; Viavattene, C.; Bogaard, T.; Ferreira, O.; Higgins, R.; McCall, R. Introduction to RISC-KIT: Resilience-increasing strategies for coasts. Coast. Eng. 2018, 134, 2-9. [CrossRef]

10. OCDE. Core Set of Indicators for Environmental Performance Reviews; OCDE: Paris, France, 1993.

11. EEA. The Changing Faces of Europe's Coastal Areas; Number No. 6 in EEA Report; European Environment Agency: Copenhagen, Denmark, 2006.

12. Patrício, J.; Elliott, M.; Mazik, K.; Papadopoulou, K.N.; Smith, C.J. DPSIR—Two Decades of Trying to Develop a Unifying Framework for Marine Environmental Management? Front. Mar. Sci. 2016, 3, 177. [CrossRef]

13. Cooper, P. Socio-ecological accounting: DPSWR, a modified DPSIR framework, and its application to marine ecosystems. Ecol. Econ. 2013, 94, 106-115. [CrossRef]

14. Wolanski, E.; Elliott, M. Estuarine Ecohydrology: An Introduction; Elsevier: Amsterdam, The Netherlands, 2015.

15. Scharin, H.; Ericsdotter, S.; Elliott, M.; Turner, R.K.; Niiranen, S.; Blenckner, T.; Hyytiäinen, K.; Ahlvik, L.; Ahtiainen, H.; Artell, J.; et al. Processes for the sustainable stewardship of marine environments. Ecol. Econ. 2016, 128, 55-67. [CrossRef]

16. Elliott, M.; Burdon, D.; Atkins, J.; Borja, A.; Cormier, R.; De Jonge, V.; Turner, R. “And DPSIR begat DAPSI (W) R (M)!"-A unifying framework for marine environmental management. Mar. Pollut. Bull. 2017, 118, 27-40. [CrossRef] 
17. Martinelli, L.; Zanuttigh, B.; Corbau, C. Assessment of coastal flooding hazard along the Emilia Romagna littoral, IT. Coast. Eng. 2010, 57, 1042-1058. [CrossRef]

18. Benassai, G.; Di Paola, G.; Aucelli, P.P.C. Coastal risk assessment of a micro-tidal littoral plain in response to sea level rise. Ocean Coast. Manag. 2015, 104, 22-35. [CrossRef]

19. Gornitz, V. Vulnerability of the East Coast, USA to future sea level rise. J. Coast. Res. 1990, 9, $201-237$.

20. Gornitz, V.M.; Daniels, R.C.; White, T.W.; Birdwell, K.R. The development of a coastal risk assessment database: Vulnerability to sea-level rise in the US Southeast. J. Coast. Res. 1994, 12, 327-338.

21. Cogswell, A.; Greenan, B.J.; Greyson, P. Evaluation of two common vulnerability index calculation methods. Ocean Coast. Manag. 2018, 160, 46-51. [CrossRef]

22. Balica, S.F.; Wright, N.G.; Van der Meulen, F. A flood vulnerability index for coastal cities and its use in assessing climate change impacts. Nat. Hazards 2012, 64, 73-105. [CrossRef]

23. Lozoya, J.P.; Sardá, R.; Jiménez, J.A. A methodological framework for multi-hazard risk assessment in beaches. Environ. Sci. Policy 2011, 14, 685-696. [CrossRef]

24. Torresan, S.; Critto, A.; Dalla Valle, M.; Harvey, N.; Marcomini, A. Assessing coastal vulnerability to climate change: Comparing segmentation at global and regional scales. Sustain. Sci. 2008, 3, 45-65. [CrossRef]

25. Vousdoukas, M.I.; Mentaschi, L.; Voukouvalas, E.; Verlaan, M.; Feyen, L. Extreme sea levels on the rise along Europe's coasts. Earth's Future 2017, 5, 304-323. [CrossRef]

26. Vousdoukas, M.I.; Mentaschi, L.; Voukouvalas, E.; Verlaan, M.; Jevrejeva, S.; Jackson, L.P.; Feyen, L. Global probabilistic projections of extreme sea levels show intensification of coastal flood hazard. Nat. Commun. 2018, 9, 1-12. [CrossRef]

27. Nicholls, R.; Wilson, T. Integrated impacts on coastal areas and river flooding. In Regional Climate Change Impact and Response Studies in East Anglia and North West England (RegIS); UK Climate Impacts Programme (UKCIP): Oxford, UK, 2001; pp. 54-103.

28. Archetti, R.; Bolognesi, A.; Casadio, A.; Maglionico, M. Development of flood probability charts for urban drainage network in coastal areas through a simplified joint assessment approach. Hydrol. Earth Syst. Sci. 2011, 15, 3115. [CrossRef]

29. Apollonio, C.; Bruno, M.F.; Iemmolo, G.; Molfetta, M.G.; Pellicani, R. Flood Risk Evaluation in Ungauged Coastal Areas: The Case Study of Ippocampo (Southern Italy). Water 2020, 12, 1466. [CrossRef]

30. Damiani, L.; Saponieri, A.; Valentini, N. Validation of swash model for run-up prediction on a natural embayed beach. Ital. J. Eng. Geol. Environ. 2018, 2018, 27-37.

31. Saponieri, A.; Di Risio, M.; Pasquali, D.; Valentini, N.; Aristodemo, F.; Tripepi, G.; Celli, D.; Streicher, M.; Damiani, L. Beach profile evolution in front of storm seawalls: A physical and numerical study. Coast. Eng. Proc. 2018, 36, 70. [CrossRef]

32. Malcangio, D.; Melena, A.; Damiani, L.; Mali, M.; Saponieri, A. Numerical study of water quality improvement in a port through a forced mixing system. WIT Trans. Ecol. Environ. 2017, 220, 69-80.

33. Baldock, D.; Beaufoy, G.; Bennett, G.; Clark, J. Nature Conservation and New Directions in the EC Common Agricultural Policy: The Potential Role of EC Policies in Maintaining Farming and Management Systems of High Nature Value in the Community; Institute for European Environmental Policy: Bruxelles, Belgium, 1993.

34. Pellicani, R.; Miccoli, D.; Spilotro, G.; Gallipoli, M.R.; Mucciarelli, M.; Bianca, M. Dynamic response of a rocky cliff under the sea wave pulse: A study along the Adriatic coast of Polignano (Apulia, Italy). Environ. Earth Sci. 2015, 73, 6243-6257. [CrossRef]

35. Piscopia, R.; Inghilesi, R.; Panizzo, A.; Corsini, S.; Franco, L. Analysis of 12-year wave measurements by the Italian Wave Network. In Coastal Engineering 2002: Solving Coastal Conundrums; World Scientific: Singapore, 2003; pp. 121-133.

36. Damiani, L.; Bruno, M.F.; Molfetta, M.G.; Nobile, B. Coastal zone monitoring in Apulia region: First analysis on meteomarine climate. In Proceedings of the 5th International Symposium on Environmental Hydraulics (ISEH 2007), Tempe, AZ, USA, 4-7 December 2007.

37. Saponieri, A.; Valentini, N.; Damiani, L.; Amoruso, V. Wave energy potential offshore Apulian coasts (Italy). In Proceedings of the Twenty-fifth International Ocean and Polar Engineering Conference, Kona, HI, USA, 21-26 June 2015; International Society of Offshore and Polar Engineers: Mountain View, CA, USA, 2015.

38. Damiani, L.; Petrillo, A.; Ranieri, G. Management of coastal area in Apulia Region. Landsc. Water Hist. Innov. Sustain. Des. 2002, 1, 71-80. 
39. Pasquali, D.; Bruno, M.; Celli, D.; Damiani, L.; Di Risio, M. A simplified hindcast method for the estimation of extreme storm surge events in semi-enclosed basins. Appl. Ocean Res. 2019, 85, 45-52. [CrossRef]

40. Bruno, M.F.; Molfetta, M.G.; Pratola, L.; Mossa, M.; Nutricato, R.; Morea, A.; Nitti, D.O.; Chiaradia, M.T. A combined approach of field data and earth observation for coastal risk assessment. Sensors 2019, 19, 1399. [CrossRef]

41. Ramieri, E.; Hartley, A.; Barbanti, A.; Santos, F.D.; Gomes, A.; Hilden, M.; Laihonen, P.; Marinova, N.; Santini, M. Methods for assessing coastal vulnerability to climate change. ETC CCA Tech. Pap. 2011, 1, 1-93.

42. Valentini, N.; Saponieri, A.; Damiani, L. A new video monitoring system in support of Coastal Zone Management at Apulia Region, Italy. Ocean Coast. Manag. 2017, 142, 122-135. [CrossRef]

43. Valentini, N.; Saponieri, A.; Molfetta, M.G.; Damiani, L. New algorithms for shoreline monitoring from coastal video systems. Earth Sci. Inform. 2017, 10, 495-506. [CrossRef]

44. Malcangio, D.; Donvito, C.; Ungaro, N. Statistical analysis of bathing water quality in Puglia Region (Italy). Int. J. Environ. Res. Public Health 2018, 15, 1010. [CrossRef] [PubMed]

45. Mali, M.; Malcangio, D.; Dell'Anna, M.M.; Damiani, L.; Mastrorilli, P. Influence of hydrodynamic features in the transport and fate of hazard contaminants within touristic ports. Case study: Torre a Mare (Italy). Heliyon 2018, 4, e00494. [CrossRef] [PubMed]

46. Damiani, L.; Petrillo, A.; Ranieri, G. The erosion along the Apulian coast near the Ofanto river. WIT Trans. Built Environ. 2003, 70, 12.

47. Saponieri, A.; Valentini, N.; Di Risio, M.; Pasquali, D.; Damiani, L. Laboratory Investigation on the Evolution of a Sandy Beach Nourishment Protected by a Mixed Soft-Hard System. Water 2018, 10, 1171. [CrossRef]

48. Apulia Region. Piano Regionale Delle Coste (PRC). 2008. Available online: http://www.sit.puglia.it (accessed on 4 June 2020).

49. Piscitelli, C.; Rotondo, F.; Selicato, F.; Selicato, S. Planning the coastal management. The Apulia Region Plan. In Proceedings of the 2014 International Conference on Civil Engineering, Santorini Island, Greece, 17-21 July 2014.

50. Gari, S.R.; Newton, A.; Icely, J.D. A review of the application and evolution of the DPSIR framework with an emphasis on coastal social-ecological systems. Ocean Coast. Manag. 2015, 103, 63-77. [CrossRef]

51. Bruno, M.; Molfetta, M.; Petrillo, A. The influence of interannual variability of mean sea level in the Adriatic Sea on extreme values. J. Coast. Res. 2014, 70, 241-246. [CrossRef]

52. Apulian Regional Watershed Authority. Piano Stralcio di Assetto Idrogeologico (PAI). 2005. Available online: http:/ / www.adb.puglia.it (accessed on 4 June 2020).

53. Nitti, D.O.; Nutricato, R.; Lorusso, R.; Lombardi, N.; Bovenga, F.; Bruno, M.F.; Chiaradia, M.T.; Milillo, G. On the geolocation accuracy of COSMO-SkyMed products. In SAR Image Analysis, Modeling, and Techniques $X V$; International Society for Optics and Photonics: Washington, DC, USA, 2015; Volume 9642, pp. 69-80.

54. Valentini, N.; Damiani, L.; Molfetta, M.G.; Saponieri, A. New coastal video-monitoring system achievement and development. Coast. Eng. Proc. 2017, 1, 11. [CrossRef]

55. Armaroli, C.; Duo, E. Validation of the coastal storm risk assessment framework along the Emilia-Romagna coast. Coast. Eng. 2018, 134, 159-167. [CrossRef]

56. Valentini, N.; Saponieri, A.; Danisi, A.; Pratola, L.; Damiani, L. Exploiting remote imagery in an embayed sandy beach for the validation of a runup model framework. Estuar. Coast. Shelf Sci. 2019, 225, 106244. [CrossRef]

57. Cooper, J.; McLaughlin, S. Contemporary multidisciplinary approaches to coastal classification and environmental risk analysis. J. Coast. Res. 1998, 14, 512-524.

(C) 2020 by the authors. Licensee MDPI, Basel, Switzerland. This article is an open access article distributed under the terms and conditions of the Creative Commons Attribution (CC BY) license (http:// creativecommons.org/licenses/by/4.0/). 